\title{
A CONSTITUIÇÃO DO SISTEMA DEMOCRÁTICO E ECONÔMICO
}

\section{THE CONSTITUTION OF THE DEMOCRATIC AND ECONOMIC SYSTEM}

\author{
Ismael Lemes Vieira Júnior
}

RESUMO: A Constituição Federal de 1988 completou mais I (um) ano de vigência sua temporada, completando assim 32 (trinta e dois) anos. Consequentemente, a democracia é um conceito político e jurídico, um valor cultural, é imediatamente impactado pela funcionalidade financeira do país. Para todos aqueles que têm dinheiro para escolher a seleção de suas refeições, o direito de escolher é importante. Para todos aqueles que recebem o prato preparado, a liberdade de escolha é um princípio simples. A Constituição, porém, não parou por aí, pois, além de garantir direitos específicos e impor restrições às ações condicionantes, consagrou muitos direitos adicionais previdenciários, ambientais e sociais. A Magna Carta, promulgada em cinco de outubro de 1988 , administrou todas as facetas do viver para a sociedade moderna, e também, mesmo assim, acaba desejando mudanças regulares. Se a Constituição foi promulgada, o Brasil era uma nação econômica e politicamente fechada. Os obstáculos ao comércio global eram de diferentes ordens, regularmente com o objetivo de impedir o câmbio. O Brasil não tirou vários dólares e também, consequentemente, a capacidade de digerir as notícias que vinham do exterior era extremamente mínima.

PALAVRAS-CHAVE: Constituição Federal de 1988. Econômico. Direitos Sociais. Direitos Fundamentais e Ambientais.

ABSTRACT: The Federal Constitution of 1988 completed another I (one) year of its term, thus completing 32 (thirty-two) years. Consequently, democracy is a political and legal concept, a cultural value, it is immediately impacted by the country's financial functionality. For all those who have the money to choose the selection of their meals, the right to choose is important. For all those who receive the prepared dish, freedom of choice is a simple principle. The Constitution, however, did not stop there, because, in addition to guaranteeing specific rights and imposing restrictions on conditioning actions, it enshrined many additional social, environmental and social rights. The Magna Carta, promulgated on October 5, 1988, managed all facets of living for modern society, and also, even so, ended up desiring regular changes. If the Constitution was enacted, Brazil was an economically and politically closed nation. The obstacles to global trade were of different orders, regularly with the aim of preventing exchange rates. Brazil did not take several dollars and also, consequently, the ability to digest the news that came from abroad was extremely minimal.

KEYWORDS: Federal Constitution of 1988. Economic. Social rights. Fundamental and Environmental Rights.

\footnotetext{
I Bacharel em Administração. Bacharel em Direito. Pós-Graduado em Docência Universitária, Especialista em Sistema de Garantias dos Direitos Fundamentais de Criança e Adolescente, Pós-Graduado em Marketing Educacional, Pós-Graduado em Logística Empresarial. Mestre em Ciências da Educação. e-mail: ismael.jr@terra.com.br. Lattes: http://lattes.cnpq.br/36449o8o8738972o Orcid: https://orcid.org/oooo-ooo24434-6762. Professor de Graduação e Pós-Graduação Faculdade Albert Einstein. E-mail: ismael.jr@terra.com.br
} 


\section{INTRODUÇÃO}

Antes de adentrar do tema será feito uma breve conceituação da Constituição e sistema democrático e econômico afim de entender o que se buscar com este artigo. Uma constituição serve para prevê direitos e garantias de um povo contra o arbítrio estatal, assim como aconteceu nas primeiras dimensões da história dos direitos fundamentais, também com o dilema "liberdade, igualdade e fraternidade" do welfare stations.

A Constituição Econômica de 1988 consiste no fundamento constitucional do sistema econômico, previsto nos artigos 170 a 192 da Constituição. Abrange os princípios de ordem econômica, política urbana, agrícola e de posse da terra; reforma agrária e do sistema financeiro nacional e se comunica com todo o sistema de direitos fundamentais, sejam eles civis e políticos, sociais, econômicos, culturais, ambientais, solidários e democráticos, tecnológicos, individuais ou coletivos. O simples debate sobre os riscos democráticos é um sinal de sentido de grande parte da população do país. Num regime unificado, não há dúvidas: tudo está sob o controle da lei, a liberdade não é apenas formal, e os meios de comunicação e notícias não são perseguidos ou favorecidos, não há apelo à intervenção militar, tem-se também o risco da democracia na era digital, o que será abordado a seguir no artigo.

O objetivo geral busca estudar o tema "a constituição do sistema democrático e econômico".

Já os objetivos específicos, analisar o que é Constituição, estudar o que é sistema democrático e por último estudar a constituição do sistema democrático e econômico. A problematização do artigo fica embasado em como trazer avanços para a constituição do sistema democrático e econômico sem violar direitos e garantias individuais das pessoas?

A metodologia utilizada para a realização do artigo foi a bibliográfica explorativa. Tal pesquisa, busca embasar seus conceitos em livros, periódicos de teses, dissertações, artigos da internet, revistas acadêmicas e demais fontes avaliadas pela Plataforma Sucupira do Governo Federal a qual é ligada ao CAPES. Assim, as revisões bibliográficas, buscam reconhecer e avaliar as evidências científicas a respeito de determinado assunto, para garantir que o pesquisador possa acessar imediatamente o que está escrito, relatado e registrado sobre o assunto. Nesse sentido, por meio do feedback bibliográfico narrativo, é possível utilizar uma nova forma de enfocar o design e também tirar conclusões modernas (MARTINS; PINTO, 200I) \& (LAKATOS; MARCONI, 2007). 


\section{A CONSTITUIÇÃO DO SISTEMA DEMOCRÁTICO E ECONÓMICO}

\section{I CONCEITO DE CONSTITUIÇÃO}

O Brasil teve 7 constituições, a de 1824 - 1891 - 1934-1937-1946-1967-1988. Assim, uma constituição é o conjunto de regras legítimas que estão a parte superior da hierarquia de direito de um estado, e que pode ou até mesmo não ser codificado como um documento escrito.

Geralmente, a constituição enumera e também restringe os poderes, bem como características do Estado, e, portanto, forma, constitui, ou seja, a entidade que é o fato de Estado. $\mathrm{Na}$ situação das nações (denominação coloquial do Estado nacional soberano) bem como nas áreas independentes das nações, a palavra descreve particularmente uma constituição que descreve a política essencial, conceitos políticos, e também estabelece o quadro, métodos, direitos e poderes de um governo. Ao restringir o alcance do próprio governo, muitas constituições garantem direitos particulares para os indivíduos. A palavra constituição poderia ser colocada no sistema mundial de leis que determinam o desempenho de um governo, que inclui várias constituições históricas e não codificadas que estavam por aí antes do aperfeiçoamento das constituições contemporâneas. (SMANIA, 2008).

A constituição complexa ou rígida é o fato de que pode ser encontrada no teto da pirâmide normativa, bem como não pode ser personalizada pelos mesmos métodos da legislação infra constitucional, e também é verdadeira para várias quantidades de direitos políticos. (LIMA, 20Io). Eles estão presentes a nível nacional (por exemplo, a Constituição codificada do Canadá, a Constituição não codificada do Reino Unido), por exemplo, a nível local (a Constituição Estadual do Rio de Janeiro), e muitas vezes em níveis mais baixos. Além disso, descreve os diferentes grupos políticos e outros, como partidos políticos, direitos fundamentais, direitos religiosos e etc.

A última Constituição do Brasil, é a supranacional, (por exemplo, a Constituição da União Europeia é promulgada). Entre as doutrinas do direito internacional admite uma relativização da soberania completa das nações contemporâneas, presumindo que a Constituição pode ser restringida por tratados internacionais, como a Convenção Americana sobre Direitos Humanos, bem como a Convenção Europeia sobre Direitos Humanos, que une as quarenta e sete nações membros do Conselho da Europa.

Como exemplo da presença de constituições em menor quantidade em relação à do Estado soberano, temos a separação de nações em estados independentes, neste caso o Brasil, de acordo com o artigo Io que narra os fundamentos da Constituição, assim, “ a República Federativa do Brasil, criada pela união indissolúvel de Municípios e Estados, bem como do Distrito Federal, constitui um Estado Democrático de Direito e tem como fundamentos seus” ( ,...). 
Consequentemente, nos Estados Federativos, além da Constituição Federal, temos Constituições para cada Estado Federado, sujeitos às disposições da Constituição Federal. É o poder constituinte derivado resultante.

A constituição teve sua origem através do artigo $5^{\circ}$ da Declaração Universal dos Direitos dos Povos da ONU prevê que cada indivíduo tenha o direito inalienável e inalienável à autodeterminação. Esta declaração em particular tem como um princípio que não são os Estados que estabelecem as diretrizes desses direitos, embora os próprios indivíduos, com suas demandas e exigências. $\mathrm{O}$ conceito constitucional contemporâneo - um certo método para restringir a força para aplicações de garantia, a partir do significado do constitucionalista português José Gomes Canotilho - tem a origem de sua nas revoluções francesas e americanas e coincide com a afirmação dos direitos básicos.

\subsection{SISTEMA DEMOCRÁTICO}

A democracia é um tipo de governo onde outros detêm o poder de selecionar a legislação que os rege. Quem são os indivíduos e como o poder é discutido entre eles são problemas centrais para o conceito democrático, a constituição e o desenvolvimento. Uma série de pedras angulares desses problemas são a liberdade de expressão e de reunião, igualdade e inclusão, voto, consentimento, filiação, à vida e também direitos das minorias.

Em geral, encontrará 2 tipos de democracia: representativa e direta. Em uma democracia imediata, os indivíduos deliberam e julgam especificamente a legislação. Em uma democracia representativa, os representantes são eleitos pelo povo para deliberar e julgar a legislação, como na democracia presidencial ou parlamentar. A democracia líquida funde elementos desses 2 tipos fundamentais. No entanto, o substantivo "democracia" foi, com o passar do tempo, alterado por mais de 3.500 adjetivos, o que implica que ele pode ter tipos que podem iludir e também omitir essa dualidade particular. (GAGNON, 2020).

Provavelmente, a estratégia de tomada de decisão diária mais típica das democracias é a maioria das regras, embora muitos outros métodos de geração de decisão, como a maioria absoluta e também a opinião, sejam igualmente essenciais para as democracias. Eles fornecem o objetivo essencial de inclusão e legitimidade mais ampla em questões muito delicadas, contrabalançando o majoritarismo e, portanto, têm precedência principalmente em um nível de aptidão constitucional.

$\mathrm{Na}$ variante popular da democracia liberal, as corridas da maioria são elaboradas na estrutura de uma democracia representativa, embora a maioria seja limitada pela constituição e proteja a minoria, normalmente através do gozo de muitos de alguns direitos específicos, por exemplo, independência de fala ou talvez independência de associação. 
A democracia é um método de processamento de conflitos onde os resultados dependem do que os indivíduos fazem, embora nenhuma força individual controle o que acontece e os resultados disso. A ansiedade dos resultados é natural na democracia. A democracia pode fazer com que cada força lute frequentemente para apreciar os interesses deles e devolve a força de grupos de indivíduos a conjuntos de regras. A democracia ocidental, única daquela que existia nas sociedades prémodernas, é geralmente considerada como tendo se originado em cidades-estados como a Atenas Clássica e também a República Romana, nas quais diferentes graus e esquemas de emancipação da população masculina gratuita foram encontrado antes do tipo desapareceu no Ocidente no início da antiguidade tardia. O termo em inglês data do século I6, do antigo francês médio e seus equivalentes do latim médio.

Com base no pesquisador político americano Larry Diamond, a democracia inclui 4 elementos que são essenciais: um programa político para selecionar e mudar o governo por meio de eleições livres e justas; o envolvimento ativo das pessoas, como cidadãos, na vida cívica e na política; proteção dos direitos humanos de todas as pessoas; um princípio de direito, em que as leis e também os procedimentos se aplicam da mesma forma que a outros cidadãos. (DIAMOND, 2004). Todd Landman, no entanto, chama a atenção dos nossos para o facto de os direitos humanos e a democracia serem 2 ideias diversas e que "deveria haver uma maior especificidade na conceptualização juntamente com a operacionalização da democracia e dos direitos humanos”. (LANDMAN, 2008).

\subsection{CONSTITUIÇÃO DO SISTEMA DEMOCRÁTICO E ECONÔMICO}

\subsection{O Princípio da Democracia Econômica, Social e Cultural}

A conexão entre a democracia e também a economia é crucial para a compreensão da ordem econômica mundial atual, marcada por tarefas de intensa integração das economias nacionais, profundo movimento de expansão e capital do sistema cambial global: a democracia não alcança as conquistas desejadas sem ter um negócio econômico que lhe seja favorável.

Nesse contexto particular, a democracia econômica surge como uma ótica de garantir a participação livre e igualitária de todos os agentes econômicos no ambiente de mercado. O modelo financeiro descentralizado da existência e do mercado de uma constituição econômica que garanta a conformação de conceitos baseados em um sistema econômico democrático, bem como o exercício dos direitos sociais e econômicos, e a funcionalidade do Estado no sistema econômico e nas relações de seu com a entidade privada, acredita papel que é importante na defesa de uma possível democracia financeira. 
A Constituição Brasileira de 1988 , ao dar os princípios norteadores da ordem financeira nacional, a regulamentação financeira e também os mecanismos de combate ao mau uso do poder financeiro, constitui um meio adequado para o aperfeiçoamento de um sistema econômico amparado pela democracia de direitos do sistema econômico. Assim, a cultura em prol da libertação do medo e da miséria é enfatizada por meio da implementação de condições que permitam a cada um desenvolver suas potencialidades e usufruir de direitos econômicos, sociais e culturais, bem como de direitos civis e políticos.

Nesse sentido, a democracia financeira é uma filosofia socioeconômica que se propõe a transportar o poder de decisão dos acionistas e gestores da empresa para um conjunto maior de públicos de relacionamento que inclui funcionários, fornecedores, clientes, amigos e também o público normal. Absolutamente nenhuma abordagem ou definição única cobre a democracia financeira. A maioria dos proponentes argumenta que as associações contemporâneas externalizam despesas, subordinam o bem-estar básico à receita pessoal e também refutam o processo político como um discurso democrático nas decisões de política econômica. Junto com essas preocupações morais, a democracia financeira tende a fazer declarações úteis, como se fosse capaz de compensar o capitalismo na lacuna de necessidade inerente altamente eficaz. (SMITH, 2005).

Os proponentes da democracia econômica geralmente argumentam que o capitalismo contemporâneo ocasionalmente leva a crises econômicas reconhecidas por uma deficiência na demanda altamente efetiva, uma vez que a sociedade moderna não é capaz de gerar renda suficiente para comprar sua produção. Porém o meio mais eficaz nos dias de hoje é o capitalismo, ensejando maior renda e economia entre os países, muitos países comunistas e socialistas vivem em "uma falsa percepção da realidade". O monopólio da empresa sobre a energia típica frequentemente produz escassez sintética, levando a desequilíbrios socioeconômicos que restringem a capacidade dos trabalhadores de acessar oportunidades financeiras e também reduzem o poder de compra do cliente.

A democracia econômica continua a ser recomendada como parte de ideologias socioeconômicas mais amplas, como um princípio independente e como um conjunto de agendas de reforma. Por exemplo, como método de garantir quase todos os direitos financeiros, abre caminho para direitos políticos totais, descritos como semelhantes. (SMITH, 2005). Teorias de mercado e não de mercado da democracia financeira foram recomendadas. Como uma agenda de reforma, o apoio a exemplos e teorias do mundo real da liberalização e descentralização econômica à regionalização, comércio justo, bancos públicos e privados e cooperativas democráticas de alimentos, bem como geração de moeda e etc. 


\subsection{PODER DE MONOPÓLIO CONTRA O PODER DE COMPRA}

Em uma perspectiva de democracia social e econômica sobre os problemas sociais, Douglas P. Biklen afirma:

O tema do lucro substituindo o bem-estar individual flui por meio dessa visão antimonopólio dos problemas sociais. Por um lado, as pessoas pobres e de renda média têm suas vidas deformadas por sua escassa ou inexistente capacidade de pagar por bens e serviços. Os ricos, por outro lado, descobrem que sua posição relativa, em termos de riqueza e poder, cresce com sua capacidade de manter o abismo entre as classes sociais. Assim, os monopólios ou a riqueza concentrada desempenham um grande papel na criação de problemas sociais. De fato, pode-se dizer, monopólios e políticas que promovem o primeiro ou concentrações de riqueza são o problema. ${ }^{[16]}$

O assunto da economia é principalmente o estudo da gestão da escassez, assim como o estudo do comportamento humano como a ciência da relação entre o definitivo e a escassez significa que ele tem usos alternativos. $\mathrm{Na}$ ausência de escassez e uso alternativo dos recursos disponíveis, muitos analistas dizem que não há problema econômico. "Embora considerasse essas funções como erros públicos, Kellogg também confirmou que o público tem a responsabilidade de encontrar e implementar soluções. Monopólio, algumas pessoas pensam que esse "erro público" é o fator mais influente da escassez humana, por exemplo, Henry $\cdot$ George ainda sugeriu:

Na realidade, não há conflito entre trabalho e capital; o verdadeiro conflito é entre trabalho e monopólio ... Abolir o monopólio que próbe os homens de se empregar e o capital não poderia oprimir o trabalho ... [R] Emover a causa daquela injustiça que priva o trabalhador do capital que seu trabalho cria e a nítida distinção entre capitalista e trabalhador deixaria de existir, de fato. (BIKLEN, 1983, p. 44).

Por exemplo, muitos analistas pensam na criação para ser um "depósito de consciência basicamente livre, tomado pelo capital monopolista e protegido para ajudar a torná-lo secreto, assim como uma" mercadoria incomum e também limitada ", no mercado a preços de monopólio, criação, um custo é colocado sobre eles não porque são limitados, mas limitando-os para indivíduos que desejam fazer uso deles. " Monopólios de patentes aumentam as taxas de participação acima do valor físico de trabalhos. A distinção entre a importância do trabalho e o valor do monopólio aumenta as taxas dos produtos e é coletado como "lucro" por intermediários que nada contribuíram para obtê-lo. (SMITH, 2007).

Os analistas geralmente concordam que condições assim geralmente levam a um déficit na demanda altamente efetiva. $O$ trabalho não ganha o suficiente para comprar o que as empresas produzem. Com base em Jack Rasmus, redator do Trillion Dollar Income Shift, em junho de 2006 nos Estados Unidos da América - EUA o banco de investimento Goldman Sachs relatou: "a principal contribuição para provavelmente as maiores margens de lucro nos últimos 5 anos é um declínio na participação do Trabalho na renda nacional." (RASMUS, 2007). 


\subsection{A ORDEM ECONÔMICA NA CONSTITUIÇÃO DE 1988}

A Carta Magna de 1988 dedica o Título VII à Ordem Econômica, compreendendo os artigos do 170 a 192. $\mathrm{O}$ art. I70 diz que a ordem econômica brasileira tem como base a valorização da livre iniciativa e do trabalho humano, com o objetivo de garantir uma presença digna para aqueles, de acordo com os ditames da justiça social. Esse tipo de objetivos e fundamentos, embora contraditórios e também ambivalentes, criam um elo organizado para o intérprete constitucional, e esse é o significado de um par de normas programáticas, em uma Constituição proeminente.

Para Eros Roberto Grau, a ordem econômica, embora oposta à ordem autorizada, pode ser usada para se relacionar com uma porcentagem da ordem jurídica, e que compense um sistema de regras e princípios, compreendendo uma ordem pública, uma ordem pessoal, uma ordem econômica e uma ordem pública (GRAU, 2004).

André Ramos Tavares, que também concebe a ordem financeira com uma compra legal do sistema econômico, descreve-a como "a expressão associada a um determinado plano financeiro, dentro de uma determinada estrutura financeira, legalmente predeterminada. É sua estrutura de compra, composta por um par de componentes que confronta um sistema financeiro. "(TAVARES, 2006).

José Afonso da Silva alega que a ordem financeira, incorporada na atual Constituição da nossa, é um tipo financeiro capitalista, uma vez que repousa completamente na apropriação pessoal do caminho da produção, bem como no esforço (SILVA, 20oI). Em outro sentido, Raul Machado Horta diz que a cópia constitucional na ordem financeira está "impregnada de conceitos inconsistentes. Hoje em dia ele espelha um curso de formação do capitalismo liberal, consagrando os valores básicos passa para o intervencionismo sistemático, bem como para a liderança de preparação, com componentes de mistura "(HORTA apud MORAES, 2008, p. 796.).

Assim como preconiza o art. 170 da Constituição Federal de 1988, in verbis:

A ordem econômica, fundada na valorização do trabalho humano e na livre iniciativa, tem por fim assegurar a todos existências dignas, conforme os ditames da justiça social, observados os seguintes princípios: (BRASIL, 2020).

I - Soberania nacional; (BRASIL, 2020).

II - Propriedade privada; (BRASIL, 2020).

III - Função social da propriedade; (BRASIL, 2020).

IV - Livre concorrência; (BRASIL, 2020).

V - Defesa do consumidor; (BRASIL, 2020).

VI - Defesa do meio ambiente, inclusive mediante tratamento diferenciado conforme o impacto ambiental dos produtos e serviços e de seus processos de elaboração e prestação;

VII - Redução das desigualdades regionais e sociais; (BRASIL, 2020). 
VIII - Busca do pleno emprego; (BRASIL, 2020).

IX - Tratamento favorecido para as empresas de pequeno porte constituídas sob as leis brasileiras e que tenham sua sede e administração no País. (BRASIL, 2020).

Parágrafo único. É assegurado a todos o livre exercício de qualquer atividade econômica, independentemente de autorização de órgãos públicos, salvo nos casos previstos em lei. (BRASIL, 2020).

Assim, pela leitura do dispositivo constitucional, pode-se inferir que a ordem econômica Constitucional brasileira se baseia na valorização do trabalho humano e na livre iniciativa privada, sendo assim, o Brasil um país capitalista.

\subsection{LIVRE INICIATIVA ECONÔMICA}

A livre iniciativa econômica é a capacidade dos indivíduos em uma cultura de realizar ações financeiras. Esta é uma frase aplicada a discussões políticas e econômicas, e também na filosofia da economia. Uma abordagem à liberdade financeira está fora da tradição liberal que destaca os mercados totalmente livres, a propriedade privada e o livre comércio sob a livre iniciativa. Mais um método de independência financeira estende a pesquisa do sistema econômico de bem-estar de escolha específica, com maior independência financeira originada de um leque maior de escolhas potenciais. Outras concepções de independência financeira incluem flexibilidade para querer, bem como independência para participar de negociações coletivas. (JACOBY, 1998).

A perspectiva liberal do mercado livre descreve a independência financeira como a flexibilidade para criar, trocar e comer alguns serviços e bens adquiridos sem o uso da força, roubo ou fraude. Isso está consubstanciado no Estado de direito, na liberdade contratual e nos direitos de propriedade e é caracterizado por mercados internos e abertos, proteção dos direitos de propriedade e independência de iniciativa financeira. Existem muitos índices de independência financeira que buscam determinar a independência financeira do mercado livre.

De acordo com essas classificações, pesquisas correlativas descobriram que um maior desenvolvimento econômico está ligado a pontuações mais altas nas classificações nacionais. No que diz respeito a vários outros métodos, como igualdade, corrupção, violência social e política, bem como a correlação deles com a independência financeira, argumentou-se que os índices de liberdade financeira combinam políticas não relacionadas e resultados de políticas para ocultar correlações entre liberdade econômica e crescimento econômico em certos subcomponentes.

Com base na perspectiva liberal do mercado livre, um método protegido de direitos de propriedade privada é um componente importante da liberdade financeira. Esses métodos incluem 2 direitos primários, especificamente o apropriado para controlar, bem como fazer uso da propriedade 
e também o direito de transferir a propriedade por meios voluntários. Esses direitos fornecem aos indivíduos a chance de autonomia, bem como de autodeterminação com base nos valores pessoais de seus objetivos. O economista Milton Friedman dos EUA vê os direitos de propriedade como "o mais simples dos direitos humanos e um período de tempo importante para vários outros direitos humanos". (ROSE, 1998).

Com os direitos de propriedade protegidos, os indivíduos são livres para decidir trabalhar com os seus bens, fabricá-los e transportá-los para qualquer outra pessoa, desde que o façam voluntariamente e não lidem com força, roubo ou fraude. Expostas a essas condições, muitas pessoas são capazes de alcançar muito mais desenvolvimento individual e liberdade do que sob coerção governamental. Um método de direitos de propriedade protegidos também reduz a ansiedade e motiva a compra, produzindo condições que são favoráveis para o sucesso do sistema econômico. (BERNARD, 1997).

A evidência empírica indica que lugares com bons dispositivos de direitos de propriedade têm taxas de crescimento financeiro quase duas vezes maiores do que lugares com métodos inadequados de direitos de propriedade, o que um processo setorial com direitos de propriedade consideráveis paixões pessoais é um estado vital para a democracia. Com base em Hernando de Soto, grande parte da pobreza nos países do Terceiro Mundo é causada pela ausência de métodos de leis bem definidos e universalmente reconhecidos, bem como dos direitos de propriedade. De Soto argumenta que, devido às barreiras legais, as pessoas pobres nessas nações não podem usar os seus bens para criar muito mais riqueza. Um pensador que questionou a casa pessoal foi anarquista, um socialista e pierre-Joseph Proudhon, que argumentou que casa é roubo tanto quanto liberdade. (PIERRE-JOSEPH, 2005).

\subsection{PRINCÍPIO DA LIVRE CONCORRÊNCIA}

A lei de livre concorrência é um princípio que incentiva a buscar e manter a concorrência nos setores da economia, regulando a conduta anticompetitiva das empresas. A livre iniciativa econômica é aplicada via aplicação pública e privada. A livre iniciativa econômica é amplamente conhecida por boas razões históricas.

A reputação da livre iniciativa econômica vai para o Império Romano. Os métodos industriais dos comerciantes da indústria, guildas; os governos geralmente têm sido sujeitos a escrutínio e, às vezes, sanções graves. Desde o século XX, a livre iniciativa econômica tornou-se global. Os 2 maiores e mais estomes; os métodos regulatórios de concorrência mais importantes serão a lei antitruste dos Estados Unidos e também a lei de correspondência da União Europeia. 
Autoridades regionais e nacionais de concorrência em todo o mundo formaram apoio internacional, bem como redes de aplicação. (TOPPING, et.al., 2013).

A livre iniciativa econômica contemporânea tem historicamente desenvolvido a nível nacional para anunciar e manter uma concorrência razoável dos mercados, particularmente nas fronteiras territoriais dos Estados-nação. A lei da concorrência nacional normalmente não cobre perseguições ao longo das fronteiras territoriais, a menos que sejam consequências consideráveis no nível do estado-nação. (TAYLOR, 2006).

Os países são capazes de permitir a jurisdição extraterritorial de situações de competição de acordo com a chamada "doutrina dos efeitos". A proteção da concorrência internacional é regida por acordos globais de concorrência. Em 1945, ao longo das negociações anteriores à aprovação do Acordo Geral sobre Comércio e Tarifas (GATT) em 1947, foram sugeridas responsabilidades de concorrência global na Carta de uma Organização Mundial do Comércio. Essas obrigações não foram incorporadas no GATT, mas em 1994, com a realização da Rodada Uruguai de negociações multilaterais do GATT, a Organização Mundial do Comércio (OMC) foi desenvolvida. O Acordo Constituinte da OMC forneceu uma série de disposições restritas sobre diferentes questões de concorrência transfronteiriço em uma base específica do setor. (TAYLOR, 2006).

O princípio da livre concorrência, tem 3 elementos primários:

- Proibição de acordos ou métodos que restringem o livre comércio e a ver com concorrência entre empresas. Isso inclui, particularmente, a repressão ao comércio livre provocada pelos cartéis.

- Proibição de comportamento abusivo por um negócio que domina um mercado, ou talvez métodos anticoncorrenciais que provavelmente resultarão em uma posição tão dominante. As práticas gerenciadas dessa forma podem incluir preços predatórios, vinculação, manipulação de preços, bem como recusa ao comércio.

- Supervisionar aquisições e fusões de grandes empresas, juntamente com algumas joint ventures. As transações consideradas como uma ameaça para o procedimento competitivo são completamente proibidas ou talvez endossadas suscetíveis a "medidas corretivas", como a obrigação de descartar com a empresa fundida ou mesmo fornecer acesso ou licenças a instalações para permitir que outras empresas continuem competindo.

A prática e o conteúdo do direito de concorrência diferem da jurisdição para a jurisdição. Proteger os interesses dos clientes (bem-estar do cliente) e fazer com que certos empresários tenham a chance de participar da economia de mercado são comumente tratados como metas que são 
importantes. A livre iniciativa econômica está fortemente ligada à lei sobre a desregulamentação da entrada em subsídios, auxílios estatais e mercados, a privatização do estabelecimento e dos ativos estatais de reguladores independentes no campo, juntamente com outras políticas voltadas para o setor de abastecimento. Nos últimos anos, a lei de correspondência continua a ser vista como um meio de oferecer serviços públicos muito melhores.

Também vale destacar que o princípio da livre iniciativa é um dos ramos do direito empresarial, além de uma ideia constitucional de ordem financeira, que visa alterar os métodos de concorrência desleal e também as ações que configuram uma infração à ordem econômica. No primeiro caso, o objeto da punição do estado é a conduta que impacta uma determinada competição, como, por exemplo, falsificação de marca, venda de qualquer item "pirateado", divulgação de informação falsa em relação a um concorrente. No próximo caso, o objeto da punição estatal é a conduta que influencia os concorrentes de forma abstrata, ou seja, o próprio ambiente competitivo, como, cartéis e etc.

Ainda que o conteúdo textual constitucional não exclua totalmente a possibilidade de intervenção do Estado no sistema econômico, o tratamento do Estado (administrador ou legislador) não pode levar ao saqueio dos conceitos de livre concorrência e de livre iniciativa, tampouco poderia deve ser realizada sem observar a distribuição constitucional de competências na Federação brasileira e também, consequentemente, a necessidade da reserva legal editada pelo ente federativo habilitado.

Adicionalmente, quanto aos limites da atividade intervencionista do Estado em relação às perseguições financeiras, não se pode esquecer que tem entendimento consolidado de que "a intervenção do Estado no sistema econômico, através da regulação e regulação dos setores financeiros, se completa com no que diz respeito aos conceitos, bem como aos fundamentos da ordem econômica".

\section{CONSIDERAÇÕES FINAIS}

Como foi destacado no decorrer do artigo, a Constituição é a lei "suprema" de uma nação, que delineia os parâmetros do sistema jurídico e também descreve os conceitos e também as instruções que regem uma cultura, economia, direitos políticos e outros. Ou seja, organiza e sistematiza um conjunto de preferências, prioridades, regras e preceitos que a sociedade pactuou. É um pacto interpessoal constitutivo de um país.

A Constituição também é chamada de Lei Fundamental ou do Estado que um povo impõe aos que a governam, para evitar o despotismo dos governantes.

A Constituição Federal de 1988 é, portanto, parte integrante da constituição política e também tem por objetivo não se confundir com uma ordem global da sociedade como os Direitos 
Humanos. A constituição brasileira tem cunho liberal e capitalista, primando pela livre concorrência e livre iniciativa.

Por conseguinte, a Constituição Federal de 1988 é a base constitucional do sistema financeiro, prevista nos artigos 170 a 192 do mesmo dispositivo legal. Abordando os conceitos de propriedade, agricultura, política urbana ou ordem econômica; a mudança agrária e também o sistema monetário nacional e também se comunica com todo o sistema de direitos básicos, sejam eles políticos e civis, sociais, econômicos, culturais, ambientais, democráticos e solidários, técnicos, coletivos ou individuais, sendo assim, a mais importante lei de um país soberano.

\section{REFERÊNCIAS}

BRASIL, 2020. Art. 170 - Atividade Legislativa. Traduzido pelo autor. Disponível em: https://www.senado.leg.br/atividade/const/coni988/conI988_07.05.2020/art_170_.asp. Acessado em: 20 de outubro de 2020 .

BERNARD H. Siegan. Propriedade e liberdade: a constituição, os tribunais e o regulamento do uso da terra. Traduzido pelo autor. Editores de transações. (1997). ISBN I-560oo-974-8 pp. 9, 230

BIKLEN, Douglas P. (1983). Organização Comunitária: Teoria e Prática. Traduzido pelo autor. Englewood Cliffs, NJ o7632: Prentice-Hall, Inc. pp. 43, 44. ISBN o-I3-I53676-I.

BORK, Robert H. (1978) The Antitrust Paradox. Traduzido pelo autor. New York Free Press ISBN o-465-00369-9

DIAMOND, L., "What is Democracy". Traduzido pelo autor. Palestra na Hilla University for Humanistic Studies, 2004.

DIAMOND, L. e MORLINO, L., A qualidade da democracia (2016). Traduzido pelo autor. Em Diamond, L., In Search of Democracy. Londres: Routledge. ISBN 978-0-415-78128-2.

GAGNON, Jean-Paul. 2020. Democracy with Adjectives Database, at 3539 entries. Traduzido pelo autor. Fornecido pela Fundação para a Filosofia da Democracia e pela Universidade de Canberra. Hospedado por Cloudstor / Aarnet / Instaclustr”.

GRAU, Eros Roberto. A ordem econômica na Constituição de 1988 (interpretação e critica). Traduzido pelo autor. 9. ed., rev. e atual. São Paulo: Malheiros, 2004.

JACOBY, Daniel (1998). Trabalhando pela liberdade: um novo olhar sobre a história do trabalho na América (e-book). Traduzido pelo autor. Armonk, NY: ME Sharpe. pp. 8-9, I48, i66-67. ISBN 978o-585-19030-3. 
LANDMAN, Todd (2018). "Democracia e direitos humanos: conceitos, medidas e relações". Política e governança. Traduzido pelo autor. 6 (I): 48. doi: I0.17645 / pag. v6ir.II86. Disponível em; https://doi.org/ro.17645/pag.v6ir.II86.

LIMA, Caroline Silva, 20ı. Qual a diferença entre constituição flexível e constituição rígida? Traduzido pelo autor. lfg. Disponível em: http://www.lfg.com.br/public_html/article.php?story=20100609160141478. Acessado em: 23 de outubro de 2020 .

MORAES. Alexandre de. Direito constitucional. 23. ed. São Paulo: Atlas, 2008.

PIERRE-JOSEPH, Proudhon. No Gods, No Masters: An Anthology of Anarchism. Traduzido pelo autor. Editado por Daniel Guerin, traduzido por Paul Sharkey. 2005. AK Press. ISBN I-904859-25-9 pp. $55-56$

RASMUS, Jack, 2007. The Trillion Dollar Income Shift, Part I. Traduzido pelo autor. Z Magazine. 20 (2): 44-49. Disponível em: http://www.armory.com/ rstevew/Wealth/JackRasmusZMag.txt. Acessado em: 29 de outubro de 2020 .

ROSE D. Friedman, Milton Friedman. Duas pessoas sortudas: memórias. Traduzido pelo autor. (1998). University of Chicago Press. ISBN o-226-26414-9 p. 6o5.

SILVA, José Afonso. Curso de direito constitucional positivo. Traduzido pelo autor. I9. ed. rev. atual. e ampl. São Paulo: Malheiros, 200I.

SMITH, J. W. (2005). Economic Democracy: The Political Struggle for the 2ist century. Radford, VA: Institute for Economic Democracy Press. Traduzido pelo autor. ISBN I-933567-0I-5.

SMITH, J.W. (2007). Money: A Mirror Image of the Economy. Traduzido pelo autor. the Institute for Economic Democracy Press. ISBN 978-I-933567-I2-9.

SMANIA, Taciana, 2008. Constituição - Conceito. Traduzido pelo autor. Taciana Smania. Disponível em: http://www.tacianasmania.com.br/2008/12/constituio-conceito.html. Acessado em: 25 de outubro de 2020 .

TAVARES, André Ramos. Direito constitucional econômico. 2. ed. rev. e atual. São Paulo: Método, 2006

TAYLOR, Martyn D. (2006). Direito internacional da concorrência: uma nova dimensão para a OMC?. Traduzido pelo autor. Cambridge University Press. p. I. ISBN 978-0-52I-86389-6. Disponível em: https://www.google.com/books?id=wTsfwxMvz_MC\&dq=competition+law\&lr=\&as_brr=3\&sour ce $=$ gbs_navlinks_s. Acessado em: 20 de outubro de 2020 . 
TOPPING, Simon; TWEEDALE, Patrick. 2013. "lei da concorrência dos emirados árabes unidos: Novos regulamentos e efeito potencial nas transações de M\&A". Traduzido pelo autor. Consultores de transação. ISSN 2329-9134. 